\title{
Coping Immigrants México-United States as an Agent of Change: From Risk to Protection Factors*
}

\author{
Angélica Ojeda García, Alma Polo Velázquez \\ Universidad Iberoamericana, Mexico City, Mexico
}

\begin{abstract}
Migration is a process that can be seen threatened or obstructed by diverse factors of risk. Its experience and survival by definition implies change. A decisive factor to achieve the good operation and the adaptation to a new culture is the confrontation strategies development. The objective of the present investigation was to identify which the confrontation strategies are used by migrants, to explore which the perception and appraisal that do of the risks are; as well as to evaluate the existing relation among both, as a way to observe the level of adaptation achieved by in a sample of 157 Mexican migrants in the United States (Riverside, L.A., C.A.), to whom applied the risk and protection factors scales (Dominguez \& Polo, in press) and the multi-dimensional and multi-situational of coping scale (Gongora \& Reyes, 1998) in short version and under a cuanti-cuali model. The results permitted to appreciate that in the case of the problem solution, strategies of the daily life are the five factors of the risk and protection factors scale; while are six factors of the coping styles scale that explain the $64.43 \%$ of the variance. With these results, we will do other analyses that show the more abuses, family vulnerability, discrimination, difficulties in the management of the language and the fear of deportation are perceived, the less they resort to direct strategies and spreads in greater measure to passive strategies and the perception of the social support is lower. The adaptative confrontation strategies development (directs and actives) can help the migrant population to face in a more efficient way the risks that are seen exposed and serve as protection factors.
\end{abstract}

Keywords: coping, risk factors, protection factors, migrants

\section{Introduction}

The Mexican migration to the United States is a process that has been taking place almost for a century and has caused an exchange among both nations (Mexico-United States) and cultures (Ariza, 2002). It is seen as mobility, a dynamic and high-risk social phenomenon (Ataca \& Berry, 1998) and it has implications for those who experience it, affecting directly: their actions, decision-making, family ties, social elections, plans of life, personal goals, insertion in the community, adaptation and social operation. Their presence obliges a restructuring of the person's identity, since it implies "changes” in their maximum expression, in the different areas that conform individual's life.

In their fight to develop an optimum social adaptation level to function, the migrants face a series of

* The material of the study is based upon work supported by a grant from the U.S. Mexico Institute at the University of California (UC MEXUS) and Mexico Health Initiative, California (CMHI) of the California Policy Research Center, Office of the President of the University of California. And the authors would like to thank Alejandra Dominguez for collecting, organizing, processing and sharing data for the present study.

Angélica Ojeda García, Ph.D., Department of Psychology, Universidad Iberoamericana.

Alma Polo Velázquez, Department of Psychology, Universidad Iberoamericana. 
stressors related with the preparation, the living of the experience, the connection and mixture or becoming rooted with the new culture. Inside these stressors can be mentioned: the reasons of migration (for example, voluntary displacement, for short or long periods, in a legal or illegal way), the moment or the phase of life in which the migration occurs (for example, by the decision of one of the members to emigrate, the readaptation in the family dynamic that it involves, the changes and widening that implies the reassignment of new or complementary social roles), the way the uprooting has taken place (for example, by the risks that they take and live by crossing the border), the welcome that they receive from the society to which they arrive, the incorporation to the receipting community (Bhugra, 2004), the insertion to the new community (Sánchez de la Barquera Vera, 1997), the way that migration experience has modified their course of life (Ariza, 2002). Because of this, a series of psychological characteristics or signs can been altered that speak of social and mental health of the migrant, which refers to the management the migrant does, the loss of nearby relations, a "known" lifestyle, a not very stable financial level, fear to be deported, dissatisfaction for lacking identity papers, vulnerability to social discrimination, uprooting feelings, low self-esteem, confusion of identity and loss of control (Bennett, Rugby, \& Boshoff, 1997).

In that sense, the migrants find themselves in the need to face a series of "crisis" situations and, therefore, to seek new forms to relate socially, new integration practices, norms and coexistence dynamics. For this, they must adopt new values, education and recreation forms, pressure to be developed and to be adapted to the change in the lifestyle, to seek an occupation that gives him purchasing power and a constant income, knowledge of the environment and new politics as "an American citizen", the establishment of new work relations and in the common environment (Bennett et al., 1997). In order to confront the new challenges, people use a great series of resources, adapting them to the new relational strategies that the environment requires (Stacey, 1990).

If a level of constructive and functional adaptation is not reached, the consequences for the migrant can be diverse and of great impact on their mental health. Due to the stress associated with those changes and, from time to time, the lack of ability to resolve these stressful situations, the migrant population has been considered like a vulnerable group of generating psychological alterations. Nevertheless and in spite of the fact that migration can weaken or break the family, social, and interpersonal relations that have been establishing, many migrants survive, and even, are fortified with this experience. The literature reports that these types of experiences are so emotionally exhausting generate an endless number of changes. Migration as a process is also a situation that promotes the growth, the strengthening and the union among the "migrant" community, such as individual and as a socially way, since resilience has been defined as the capacity of surpassing challenges presented by life, through the adequate use of his personal resources which allow him to cope the adverse situations, diminish the effects of the mentioned social problems and even prevent them in a second moment. In a parallel way, it has been observed that they adopt conducts and new strategies that help to bear the conflicts and allow them to be able to face the crisis situations, through processing the information in such a way that allows them to make adequate decisions at the precise moment (Masten, Best, \& Garmezy, 1990), or generate new models of human connection (Stacey, 1990) and express them as resilient and cognitive abilities of coping in attention, the management of the external stressors (Jaramillo-Vélez, Ospina-Muñoz, Cabarcas-Iglesias, \& Humphreys, 2005) and the type of relation that is promoted with the ones that surround him (other migrant, family, neighboring, community and church) (Richardson, 2002).

In that sense, the study of the resilient abilities in migrants has become an efficient medium for the 
understanding and living of the experience of migration. Nevertheless, in the practical territory, it has been undertaken like a construct that can be measured or observed according to the continuous presence vs. absence between risk factors and/or protection. Such is the case of Little's (s/f) Checkup type scale of Risk and Resilience of San Diego, which has been used both in young populations and adult populations. It consists of 60 points divided into six categories or generic areas, half are risk factors and the other half are protection factors: delinquency, education, family, use of substances, individual factors and relations among equals. Each category includes five protection factors (communication with the family, use of the constructive time at home, family activities and family backup) and four risk factors of poor relation with parents (parental supervision, abuse of substances by the parents and abandonment). Each point is qualified as "if", "not" and "something". The results of the risk factors and protection factors are combined with the resilience results, which mean that the high results indicate greater resilience. This instrument that counts on internal and predictive validity can be used for people of different ethnic groups. For greater data consult the reference (Turner \& Fain, 2006).

\section{Risk Factors vs. Protection}

It is known that all people and all groups (including families) are seen in the need of coping with positive and negative influences, when they develop and search to attain both personal and family and group goals. Nevertheless, for migrants, this challenge is greater, since they must "accommodate" to the additional influences and external threats, such as the contact with a new culture, the adaptation to a different environment and having to adapt their own histories inside their lives in a new country.

A risk factor can be considered as all those interpersonal, social, environmental or individual influence elements that are presented in the key environments of people and that increase the probability that an individual presents some personality disorder (Margain, Castro, \& Llanes, 2003).

Various investigations pointed out that the most common risk factors related with migration and threatened the psychological well-being and the effective adaptation of migrants. Among these factors are the use of language, discrimination perception, disintegration and changes in the family structure, addictions and substance abuse and lack of social support (Chapman \& Perreira, 2005).

The lack of control of the alien language causes that the person experiments a deterioration in his/her capacity to resolve daily problems, which has a direct impact on his/her sense of efficiency and self-esteem (Rumbaut, 1994).

The parents may experiment linguistic and cultural barriers when they communicate with their children, especially with the ones who have grown and studied in the receiving community. Parents usually have difficulties when communicating. The children, at the same time, can experiment conflicts when they are confronted by the new culture and perceive the incongruity of the expectations and values at home and in their new environment (Neto, 2001).

Discrimination is one of the factors with greater negative effects. The greater the discrimination is, the greater the incidence of negative consequences and the lower the adaptation levels are (Neto, 2002). Perceiving discrimination makes the migrant question his/her own cultural identity and decrease his/her level of self-esteem. Likewise, the greater the discrimination, the less social acceptance, which prevents the migrants' integration to the receiving culture in the long run (Arcia, Skinner, Bailey, \& Correa, 2001).

The separation between a family member and his family caused by migration has considerable effects on the family dynamic because of the disintegration that it causes and the adjustments that the whole family has to 
implement (Rumbaut, 1994).

The alterations in the family structure are many and can go from changes in gender roles to the lack of family bonding for long working days of both parents. The social support is a variable very referred to within the area of migration, since various studies have identified that this process can cause that the person, when mobilizing, loses contact with his/her family, friends and neighbors. The result is a reduction of his/her original support agents and the need to establish new contacts in the place to which he/she has arrived. This loss of important support individuals (Hovey, 2000) is a risk factor that often triggers stress and anxiety problems in the population, or when creating an inefficient social support, increases the anxiety, depression and stress levels. The networks constitute a social capital of greater utility to face the situation of implied social vulnerability in the condition of an ethic minority (Malkin, 1999).

Opposed to this, on the other side of the continuum, all those resources, internal, external or social funds which allow the individual to confront stressing situations, with the aim of manipulating, dominating, managing, controlling, diminishing their importance and impact, disappearing or reducing the adverse or stressing event, are considered as a protection factor (Walsh, 2004).

But, on the other side, specific protection factors of the migrant population have been found, such as family values (Bird, Canino, Davies, \& Zhang, 2001), the integration or biculturalism (Bush, Supple, \& Lash, 2004; Dumka, Roosa, \& Jackson, 1997). The effective use of social networks (Finch, Kolody, \& Vega, 2000) and as it has been mentioned before the effective and adaptive use of coping strategies.

From the field of traditional psychology, that is, under the dual perspective of "Health-Sickness" and inside the migrant population, Bhugra (2004) made a distinction between those elements that according to their presence vs. absence, may be considered or not as risk factors and those which from the level of intervention can favor both the individual and group functioning as protection factors.

It has been found that a decisive factor to achieve the well functioning and adaptation to a new culture, and it is overcoming the risk factors and promoting the protection ones and the development of resilient abilities and coping strategies. Because of this, the current investigation tries to detect which these inside the sample-object are.

\section{Coping Styles as a Link to Risk Factors to Protection Factors}

The strategies or coping styles are all those cognitive or behavior efforts directed to handle, through reducing, minimizing, dominating or tolerating, the internal and external demands generators of stress and negative emotions (Lazarus \& Folkman, 1984). For example, Walsh (2004) emphasized these strategies as a fundamental process for the families that are found in situations of risk.

According to Snyder (1999), coping is a dynamic process integrated so much by a psychological, emotional and physical load, to which resorts (whether in a conscious or unconscious way) by virtue of responding to the stressful events of the daily life and whose purpose is exactly to diminish the undesirable tension and the immediate stress, prevent any discomfort product of the emotional instability by external pressure and contribute to long time limit in the subjective welfare of the person.

Coping styles as strategies serve, in great measure, to meet again the subjective equilibrium of a person who lives an event as stressful. They are the reflect of the lifestyle of a person, therefore, this last one copes stressful factors, from its point of view, the interpretation and recognition do of the same.

People generally try to reach their goals, resolve their conflicts and adapt to the environment in which they 
develop to be able to have a better quality of life. How do they do it? What do they do when have problems and adversities and how much do they plan to make decisions to resolve their difficulties?

The Lazarus and Folkman's (1984) model proposed that the person uses two appreciation levels to be able to select his/her answer or coping strategy. In the first level, a primary appreciation is found, where the individual evaluates the situation and determines how threatening is and the risk that runs. In this cognitive evaluation, the external stressors, very particularly, and their possible influence or effect on the welfare of the person are analyzed. When the event is perceived as very threatening, it passed to the second level of appreciation, where what is evaluated is no longer the situation but the resources of the person to respond. In other words, depending on the evaluation of the person in these two cognitive prosecution levels, the individual decides which coping strategy implements.

Once it implemented the coping strategy, this can be operated in two ways:

(1) To be focused on the problem, what implies that all the efforts by coping them, it will be directional to change or to control what produces stress: learning new abilities, removing barriers and generating alternatives of solution;

(2) To be focused on the emotion, what implies to seek the form to cope or to handle the emotions is that awakes the stressor: seeking emotional support, changing mental plans and working the social comparison.

The use of coping strategies depends on who implement it and is in the situation. A person adopts a cultural coping strategy (typical of the place which he arrives) when the circumstances oblige to give an individual answer and there are four types: (1) instrumental strategies or confrontation or direct action: They are directed toward the management of the threat or the stressor itself; (2) intrapsychic strategies: They directed chiefly in regular or to minimize the conflict emotional companion; (3) inhibition of the action escape-avoidance: It refers to the ability to resist to take action when that same action increases the probability of damage, danger or conflict; and (4) search of information or solution planned: It involves the instrumental activity to acquire a base for the action and is also a support mobilization form that can alleviate the emotional conflict. While the circumstances oblige to respond as group, that is, socially, it expresses some coping strategies more general and typical of the place of where proceeds (Hobfoll, 1998; Ogbu, 1981) and there are two types of strategies focused on the problem, or well, on the emotion, where the first implies a "planning" that conduct the solution of the problem (Parker \& Endler, 1996) and the second refers to all those activities focused on modifying the emotional and internal reactions resultants of the stressful situation, known as distancing/avoiding (Chang, 1998).

Aldwin and Revenson (1987) carried out a longitudinal study about stress by acculturation and mental health, where they evaluated 291 migrant adults (of different countries) resident in Los Angeles, California and they found evidence on a causal cycle mutually reinforced between poor mental health and desadaptative coping strategies. While larger it is, the initial level of emotional conflict and the degree of severity of the problem is more probable than the individuals who utilize a desadaptative confrontation, increasing thus the emotional conflict and also probably the possibility on future problems. As for the coping focused on the problem is insufficient to inquire on the used strategies, more information on the results of these strategies is required.

Bouchard (2003) in his study found that people with low emotional resources, what equals to emotional conflict, resort to do a primary appraisal of the event and use more strategies focused on the emotion, with which they seek to modify themselves so that they does not impact so much on the threat situation. On the 
contrary, who they tend to analyze the problem since different perspectives, commonly they do a secondary appraisal of this and use the strategy of planning (Costa, Somerfield, \& McCrae, 1996).

The objective of the present investigation was to identify which are the coping strategies used by the migrants and explore which is the perception and appraisal that do of the risks and the existing relation among both, as well as evaluate, if those strategies can be considered as agents of change in a sample of Mexico-United States migrant, with the purpose to promote the protection factors inside this population.

Subsequently, the discussion about if the way to transform the risk factors to protection factors could be the coping strategies to the ones that a person resorts before situations of stress is presented.

\section{Method}

\section{Sample}

The sample was constituted by 157 Mexican migrants in the United States, 90 were women (57.3\%) and 67 were men (42.7\%). The age of the participants went from 18 to 60 years with an $X=35.9$ years and an $S=$ 9.6. The years of married went from one to 38, with an $X=13.3$ and $S=9.3$. Eighty-five point nine percent were married or lived in free union with their couple and the $14.1 \%$ was single. Fifty-two percent of the subjects had known to there couple at Mexico and the $48 \%$ at the United States. According to the state of origin: Jalisco (24\%), Michoacan (10.8\%), Distrito Federal (10.2\%) and Zacatecas (7.6\%), the selection of the sample was accidental non-probabilistic.

\section{Measures}

Multi-dimensional and multi-situational scale of coping styles (Góngora \& Reyes, 1998) in short version. It is a multi-dimensional and multi-situational scale that measures a stable and lasting dimension (clash as characteristic) and a second dimension, changing and temporary (clash like state of mind) with six problem situations: life (general situation), health, family, couple, friends, school and/or work (more specific situations). Each situation is conformed of 18 reagents, doing a total of 108, with a Likert format with a continuous of seven points that goes from "Always" (7) to "Never" (1).

Risk and protection factors scale (Dominguez \& Polo, in press). It is a scale conformed by 41 reagents, which were the result of a previous investigation, qualitative of focal groups with Mexican migrants in the United States as the theoretician of the literature on the matter, of which the reagents were edited, through the technique "by judges", like affirmations in Likert with three options of answer that went from very disagreement to really agree.

\section{Procedure}

Contact with organizations and institutions that work with migrant population was done and its consent for the confidential use of the information was requested. The instruments before above-mentioned were organized in battery, whose so much distribution of the scales as of the reagents by each one of them was at random.

\section{Results}

Of the analyses of frequencies and $X$ to observe the behavior of the reagents by scale was observed that all the reagents evaluated discriminated for the studied sample. At the same time, the results permit to appreciate that in the case of the problem solution, strategies of the daily life are the five factors of the risk and protection factors scale, while are six factors of the coping styles scale that explain the $64.43 \%$ of the variance. Such 
factors were submitted, each one, to the analysis of reliability to observe their level of internal consistency through the Alpha of Cronbach. Where each factor, in order of apparition and by scale, remains integrated as continues:

(1) Alterations in the family dynamics $(F 2 / \alpha=0.89)$ : Those situations where is observed that the family is less united as a result of the migration;

(2) Racial discrimination $(F 3 / \alpha=0.80)$ : Discrimination by being Mexican lacking identity papers;

(3) Difficulties in the use of the language $(F 4 / \alpha=0.77)$ : All those situations of conflict for lack of control of the language;

(4) Fear to the deportation $(F 5 / \alpha=0.83)$ : Situations caused by the lack of documents;

(5) Active confrontation $(F 1 / \alpha=0.96)$ : It is the troubleshooting strategy that implies action, since planning to reflect on it happened and the consequences of the event ask a counsel, talk him someone more the problem as a form of being clarified the ideas, implement new forms of undertaking, it to being worried and to pray;

(6) Passive coping $(F 2 / \alpha=0.69)$ : It is the strategy to respond to the problems of the daily life in an inactive way and leave the drift, waiting that it is the time who resolve them or imagine that nothing is happening;

(7) Evasive coping $(F 3 / \alpha=0.64)$ : It is the strategy of troubleshooting that implies, like its name says it, to evade the confrontation or clash of the problems through having faith that the things in some moment will be resolved by itself, of that is better to forgot of them doing other things, leave the time resolve them, or well, do as if nothing was occurring, when the person avoids, escapes or minimizes the problem or its solution;

(8) Social support coping $(F 4 / \alpha=0.74)$ : It is the strategy to respond to the problems of the daily life through the comprehension of the others, seeking through them a counsel, or clarifying the ideas. When the person asks aid or resorts to other, like friends, couples, family, etc., to face the inconveniences or difficulties;

(9) Direct-revalorative coping $(F 5 / \alpha=0.96)$ : It is the conflicts resolution strategy of the daily life that seeks to learn from these, through finding him/her the positive, analyzing them to implement different and new strategies to solve them, when the person does something to resolve the problem, trying to learn or see the positive thing of the situation;

(10) Direct coping $(F 6 / \alpha=0.93)$ : It is the strategy of troubleshooting in direct form and without detours, planning and acting at the same time, putting all the pledge so that they are solved, when the person does something to resolve the problem and face the risks;

(11) Exploitation and abuses $(F 7 / \alpha=0.91)$ : Those situations that imply labor abuses and intra-family violence.

Table 1 shows the correlation among the coping strategies with the risk factors. The data refer to, in general, a significant and negative correlation among the coping strategies directed to the resolution of the problems of the daily life, therefore, the unique one correlated positively and significantly, although low was the passive coping strategy. According to the degree of correlation, the more coping style use is the direct one, followed by the direct-revalorative and finally, by the active. Its degree of correlation goes by virtue of what more worries him/her that they are in the first place: exploitation and abuses, later the alterations or conflicts that are given inside the family nucleus, followed by the racial discrimination, difficulties for lack of the control of the English language and the one that less see as a risk factor, which is the possibility of a deportation. Consequently, it can be told that as for the factors of risk, that independently of which this be, that is to say, among more abuses, discrimination on the part of the authorities threats to the deportation and difficulties in the control of the language or witness alterations in the family nucleus the migrant, less the ability to confront those abuses in a direct way. Because of that, they do not seek specific solutions to the problems (direct). But, neither 
does they dedicate time to reflect and seek new strategies to do it (direct revalorative), nor seek to resolve them analyzing them or planning their resolutions. On the contrary, they expect that be the time that dissolves them and they prefer to do other things for not thinking about them.

Table 1

Product Moment Correlation of Pearson for the Five Styles of Clash and the Five Risk Situations in a Sample of Mexicans Migrant in the USA.

\begin{tabular}{lllll}
\hline & $\begin{array}{l}\text { Exploitation } \\
\text { and abuses }\end{array}$ & $\begin{array}{l}\text { Alterations in the } \\
\text { family dynamic }\end{array}$ & $\begin{array}{l}\text { Racial } \\
\text { discrimination }\end{array}$ & $\begin{array}{l}\text { Difficulties in the } \\
\text { use of the language }\end{array}$ \\
\hline Social support & $-0.261^{* *}$ & -0.065 & -0.020 & 0.040 \\
feportation \\
Direct revalorative & $-0.650^{* *}$ & $-0.398^{* *}$ & $-0.293^{* *}$ & $-0.265^{* *}$ \\
Direct & $-0.661^{* *}$ & $-0.432^{* *}$ & $-0.338^{* *}$ & $-0.271^{* *}$ \\
Active & $-0.629^{* *}$ & $-0.364^{* *}$ & $-0.290^{* *}$ & $-0.211^{*}$ \\
Passive & $0.479^{* *}$ & $0.379^{* *}$ & 0.294 & $0.390^{* *}$
\end{tabular}

Notes. ${ }^{* *} p>0.05 ;{ }^{*} p>0.01$.

Table 2 shows the differences by " $t$ " of student for each one of the risk factors and coping styles resultants of this study, by the degree of expression. The data refer to alone difference for the coping styles and whose pattern refers to that when it is about active and direct resolution strategies, before the difficulties that seem to be outside of its control, the migrant are used to use them less. On the other hand, before the perception of those situations as "that do not depend on them", resorts to a form of passive coping.

Table 2

Differentiates by $t$ of Student Between Coping Styles and Risk Factors for the Studied Sample, by Degrees of Expression of the Same

\begin{tabular}{llr}
\hline Factors & Degree of presence & Media \\
\hline Direct-revalorative & Low & 10.48 \\
$(t=5.219, p=0.000)$ & High & 7.02 \\
Direct & Low & 8.36 \\
$(t=5.258, p=0.000)$ & High & 5.58 \\
Active & Low & 37.26 \\
$(t=4.758, p=0.000)$ & High & 27.18 \\
Passive & Low & 10.76 \\
$(t=5.558, p=0.000)$ & High & 13.75 \\
\hline
\end{tabular}

\section{Discussion}

The results agree with the proposed by Aldwin and Revenson (1987) with relation to that while larger the initial level of emotional conflict is, the degree of severity of the problem is more probable than the individuals who use a desadaptative coping, thus increasing the emotional conflict.

The data of this study allow to see that in the case of the studied sample of among more migrants, they perceived abuses, family vulnerability, discrimination, difficulties in the management of the language and feared to the deportation except resorts to direct strategies and spreads in greater measure to in a parallel way smaller and passive strategies is the perception of the social support. What gives an indication about how do they used to adoptive before situations that feel that are product of the context and they are not under their control (Salgado de Snyder, 2002). Finally, migration by definition implies change (Snyder, 1999) and new 
learning for who live it, as Walsh (2004) said, continuously, those families should make decisions for it, and the different coping strategies avail oneself of it.

It was found that among greater risks related to the exploitation and the abuses of the receptor culture it less tends to reflect or act to seek concrete solutions to them. Recalling that the context is important has to be taken into account that the migrant one can perceive that is not in its hands to resolve those abuses. Among more, they perceive the exploitation that they spread then to resort to passive strategies to avoid them and they are perceived with less social support.

Among the more vulnerable the family structure is found, the less they resorts to direct strategies and tends itself to leave that be the time the one that dissolve them (in the best of the cases).

In this study, it seems that the coping styles that are used to being more adaptive (the direct one, the direct-revalorative and the active), which are the less used. On the other hand, the one that seems less adaptive, the passive one, to which more resorts. Among more, the risk factors are perceived and the data indicate a greater passive coping strategies use as they are the evasion, guiltless, negation, etc.. We can assume that the sensation of impotence before risks can cause this type of conducts. Same indicates that with the alone fact to put them attention, to recognize them and/or a coping strategy be chosen, it is probable that its threatening perception be reduced, therefore, certain control is perceived and management of this situation (Aldwin \& Revenson, 1987).

As well as Lazarus and Folkman (1984) referred to be able to elect and/or to adopt one or another coping strategy, two roads exist, one focused to the problem and the other, to the emotion. In the case of the results of the present study, it seems that the migrants are focused more on the problem and upon seeing it, since they cannot handle, and they resort to strategies less adaptive. Situation coincides with other studies in similar population (Arcia, Skinner, Bailey, \& Correa, 2001; McCrae, 1991; Neto, 2002).

Nevertheless, we coincide with the idea about that the adaptive coping strategies development (active and direct) can help the migrant population to face it in a more efficient way the risks to the ones that are seen exposed and to serve as protection factors (Walsh, 2004). Of such way of any preventive program, or of psychological support, can take in consideration this evidence, since they would be consciences that they can have the power to diminish and to cope the risk factors that are in their hands.

\section{References}

Aldwin, C. M., \& Revenson, T. A. (1987). Does coping help? A reexamination of the relation between coping and mental health. Journal of Personality and Social Psychology, 53(2), 337-348.

Arcia, E., Skinner, M., Bailey, D., \& Correa, V. (2001). Models of acculturation and health behaviors among Latino immigrants to the US. Social Science and Medicine, 53(1), 41-53.

Ariza, M. (2002). Migración, familia y transnacionalidad en el contexto de la globalización: Algunos puntos de reflexión. Revista Mexicana de Sociología, 64(4), 53-84.

Ataca, B., \& Berry, J. W. (1998). Psychological, sociocultural and marital adaptation of Turkish immigrant couples in Canada (Electronic version). International Journal of Psychology, 37, 13-26.

Bennet, H., Rugby, C., \& Boshoff, A. (1997). The relationship between tenure, stress and coping strategies of South African immigrants to New Zealand. South African Journal of Psychology, 27(3), 160-165.

Bhugra, D. (2004). Migration and mental health. Acta Psychiatr Scand, 109, 243-258.

Bird, H. R., Canino, G. J., Davies, M., \& Zhang, H. (2001). Prevalence and correlates of antisocial behaviors among three ethnic groups. Journal of Abnormal Child Psychology, 29(6), 465.

Bouchard, G. (2003). Cognitive appraisals, neuroticism, and openness as correlates of coping strategies: An integrative model of adaptation to marital difficulties. Canadian Journal of Behavioral Science, 35(1), 1-12. 
Bush, K. R., Supple, A. J., \& Lash, S. B. (2004). Mexican adolescents' perceptions of parental behaviors and authority as predictors of their self-esteem and sense of familism. Marriage and Family Review, 36(1/2), 35.

Costa, P. T., Somerfield, M. R., \& McCrae, R. R. (1996). Personality and coping. In M. Zeidner, \& N. S. Endler (Eds.), Handbook of coping: Theory, research, applications (pp. 45-61). New York: John Wiley.

Chang, E. D. (1998). Dispositional optimism and primary and secondary appraisal of a stressor: Controlling for confounding influences and relations to coping and psychological and physical adjustment. Journal of Personality and Social Psychology, 74, 1109-1120.

Chapman, M. V., \& Perreira, K. M. (2005). The well-being of immigrant Latino youth: A framework to inform practice. Families in Society, 86(1), 104-110.

Dumka, L. E., Roosa, M. W., \& Jackson, K. M. (1997). Risk, conflict, mothers' parenting, and children's adjustment in low-income, Mexican immigrant, and Mexican American families. Journal of Marriage and the Family, 59(2), 309-323.

Finch, B. K., Kolody, B., \& Vega, W. A. (2000). Perceived discrimination and depression among Mexican-origin adults in California. Journal Health Social Behavior, 41(3), 295-313.

Gongora, E., \& Reyes, I. (1998). El enfrentamiento a los problemas en jóvenes adultos yucatecos. La Psicología Social en México, 7, 18-24.

Hobfoll, S. E. (1998). Stress, culture, and community: The psychology and philosophy of stress. New York: Plenum Press.

Hovey, J. D. (2000). Acculturative stress, depression, and suicidal ideation in Mexican immigrants. Culture Divers Ethnic Minor Psychol, 6(2), 134-151.

Jaramillo-Vélez, D. E., Ospina-Muñoz, Cabarcas-Iglesias, \& Humphreys, J. (2005). Resiliencia, espiritualidad, aflicción y tácticas de resolución de conflictos en mujeres maltratadas. Revista de Salud Public, 7(3), 281-292.

Lazarus, R. S., \& Folkman, S. (1984). Stress, appraisal, and coping. New York: Springer Publishing.

Malkin, V. (1999). La reproducción de relaciones en la comunidad de migrantes mexicanos en New Rochelle, Nueva York, en Gail Mummert (comp.), Fronteras fragmentadas. El Colegio de Michoacán-Centro de Investigación del Desarrollo Económico de Michoacán (CIDEM) (pp. 475-496).

Margain, M., Castro, M., \& Llanes, J. (2003). Aprendiendo a pasarla bien. México: Pax México.

Masten, A. S., Best, K. M., \& Garmezy, N. (1990). Resilience and development: Contribution from the study of children who overcame adversity. Developmental Psychopathology, 2, 425-444.

Neto, F. (2001). Satisfaction with life among adolescents from immigrant families in Portugal. Journal of Youth and Adolescence, 30(1), 53-67.

Neto, F. (2002). Social adaptation difficulties of adolescents with immigrant.

Nieto Zermeño, O. (2008). Grupo de pares de reflexión y ayuda mutua (GPRAM): Modelo emergente para la intervención comunitaria. Revista de Psicología Iberoamericana, 16(1), 36-43.

Ogbu, J. (1981). Origind of human competence: A cultural-ecological perspective. Child Development, 52, 413-429.

Parker, J. D. A., \& Endler, N. S. (1996). Coping and defense: A historical overview. In M. Zeidner, \& N. S. Endler (Eds.), Handbook of coping: Theory, research, applications (pp. 3-23). New York: John Wiley.

Richardson, G. (2002). The metatheory of resilience and resiliency. Journal of Clinical Psychology, 58(3), 307-321.

Rumbaut, R. G. (1994). The crucible within: Ethnic identity, self-esteem, and segmented assimilation among children of immigrants. The International Migration Review, 28(4), 748-756.

Salgado de Snayder, N. (2002). Research and clinical perspectives on Mexican migration: Those who go, those who stay. Journal of Multicultural Nursing and Health, 8(2), 335-346.

Sanchez de la Barquera Vera, L. B. (1997). La migración laboral e Indocumentada Mexicana a los Estados Unidos (Tesis de Licenciatura no publicada, Universidad Iberoamericana, México).

Snyder, C. R. (1999). Coping. Nueva York: Oxford University Press.

Stacey, J. (1990). Brave new families: Stories of domestic upheaval in late twentieth century. New York: Basic Books.

Turner, S., \& Fain, T. (2006). Validation of the risk and resiliency assessment in Los Angeles county probation system. Federal Probation, 70(2), 49-57.

Walsh, F. (2004). Resiliencia familiar. Buenos Aires: Amorrortu. 